\title{
Telemonitoreo y teleorientación desarrollados por el Ministerio de Salud del Perú en tiempos de pandemia por COVID 19
}

\section{Telemonitoring and teleorientation developed by Ministry of Health of Peru in times of a COVID 19 pandemic}

\author{
Liliana F. Má-Cárdenas ${ }^{1, a}$, Cynthia Tellez-Gutierrez ${ }^{1, b}$, Aurora Carrasco-Buitrón ${ }^{1, c}$, Ana C. Inglis-Cornejo ${ }^{1, d}$, \\ Mónica Romero-Arzapalo, ${ }^{1, e}$, Cecilia López-Artica ${ }^{1, f}$, Fernando Aquino ${ }^{1,9}$, Raúl Timaná-Ruiz ${ }^{2, h}$ \\ ${ }^{1}$ Dirección General de Telesalud, Referencia y Urgencias del Ministerio de Salud. Lima, Perú. \\ ${ }^{2}$ Universidad Nacional Mayor de San Marcos. Lima, Perú. \\ ${ }^{a}$ Médico gestor en salud. ORCID: https://orcid.org/0000-0002-1227-8865 \\ ${ }^{\mathrm{b}}$ Abogada, ORCID: https://orcid.org/0000-0002-9346-0094 \\ 'Economista, ORCID: https://orcid.org/0000-0001-5732-2877 \\ ${ }^{d}$ Médico gestor en salud, ORCID: https://orcid.org/0000-0002-2281-3104 \\ ${ }^{\text {e }}$ Ingeniera de redes y comunicaciones, ORCID: https://orcid.org/0000-0003-3360-3572 \\ ${ }^{\dagger}$ Médico especialista de gestión en salud, ORCID: https://orcid.org/0000-0003-1036-4310 \\ ${ }^{9}$ Ingeniero de sistemas e informática, ORCID: https://orcid.org/0000-0003-1036-4310 \\ ${ }^{\mathrm{h}}$ Médico gestor en salud y economista de la salud. ORCID: https://orcid.org/0000-0003-0693-3445
}

An Fac med. 2021;82(1):85-6. / DOI: https://doi.org/10.15381/anales.v82i1.20783

Correspondencia:

Liliana Frida Ma Cardenas

Ima@minsa.gob.pe

Recibido: 24 de junio 2021

Aprobado: 30 de junio 2021

Publicación en línea: 3 de julio 2021

Conflictos de interés: Liliana Má Cárdenas es Directora General de la Dirección General de Telesalud, Referencia y Urgencias del Ministerio de Salud del Perú.

Fuente de financiamiento: Dirección General de Telesalud, Referencia y Urgencias del Ministerio de Salud del Perú del Perú.

Contribuciones de los autores: LM concibió y diseñó la investigación, CT, $A C, A l, M R, C L, F A$ recolectaron los datos, $R T$ redactó el manuscrito, y $L M$ aprobó la versión final del artículo. RT analizó los datos y redacto las tablas y gráficos; todos los autores revisaron críticamente el artículo.

Citar como: Má-Cárdenas L, TellezGutiérrez C, Carrasco-Buitrón A, Inglis-Cornejo A, Romero-Arzapalo M, López-Artica C, et al. Telemonitoreo y teleorientación desarrollados por el Ministerio de Salud del Perú en tiempos de pandemia por COVID 19. An Fac med. 2021;82(1):85-6. DOI: https://doi.org/10.15381/anales. v82i1.20783
Sr. Editor,

La Red Nacional de Telesalud de Perú desde el 2017 viene desarrollando los 4 ejes de la telesalud. La pandemia por COVID-19 ha producido la aceleración en el uso de las tecnologías de la información dado los mecanismos de transmisión del SARS COV-2. Los sistemas de salud no han sido la excepción, las atenciones de salud han utilizado a la telesalud como medio fundamental para lograr la continuidad de la atención de las personas con enfermedades crónicas, el seguimiento a los cuidados de las enfermedades agudas y la atención de las personas que necesiten orientación sobre sus dolencias e inquietudes ${ }^{(1)}$.

La telesalud es un servicio en el cual dentro de sus ejes se encuentra el monitoreo y seguimiento de la persona usuaria, la cual toma el nombre de telemonitoreo. Este es un servicio para proporcionar a la persona usuaria consejería y asesoría con fines de promoción de la salud, prevención, recuperación o rehabilitación de las enfermedades, denominándose para ello: teleorientación ${ }^{(2)}$. El Ministerio de Salud del Perú (MINSA), debido a la pandemia repotenció su línea gratuita Infosalud de servicio telefónico y brindó monitoreo telefónico a través de las Instituciones Prestadoras de Salud (IPRESS) a nivel nacional.

En ese sentido, el objetivo de la presente carta es reportar la frecuencia de las actividades de telemonitoreo y teleorientación realizadas a nivel nacional por el MINSA y los gobiernos regionales en el año 2020. Para este fin se realizó un estudio observacional de corte transversal de todos los telemonitoreos y teleorientaciones registradas en la base del sistema de información de consulta externa (HIS) del MINSA y el sistema de información asistencial Teleatiendo de la Dirección General de Telesalud, Referencia y Urgencias del Ministerio de Salud (DIGTEL). Se utilizó estadística descriptiva para las variables mencionadas en este estudio.

En la plataforma Teleatiendo se registraron más de 186 mil telemonitoreos y más de 645 mil teleorientaciones, mientras que en el HIS MINSA se registraron 1,5 millones de telemonitoreos y 8,1 millones de teleorientaciones. Así, se registraron un total de 1,7 millones de telemonitoreos, de los cuales el $80 \%$ se registraron en personas que habitan en distritos de cuarto y quinto nivel de pobreza, y un $80 \%$ se atendieron en establecimientos de salud del primer nivel. En el caso de las teleorientaciones se registraron 8,8 millones en el periodo de pandemia, de los cuales el $75 \%$ se registraron en personas que habitan en distritos de cuarto y quinto nivel de pobreza, y el $88 \%$ se registró en el primer nivel (Tabla 1). 
Tabla 1. Telemonitoreo y teleorientación en el Ministerio de Salud del Perú, durante el año 2020, según quintil de pobreza y categoría de los establecimientos.

\begin{tabular}{|c|c|c|c|c|c|}
\hline \multirow{2}{*}{ Característica } & & \multicolumn{2}{|c|}{ Telemonitoreo } & \multicolumn{2}{|c|}{ Teleorientación } \\
\hline & & $\mathbf{N}^{\circ}$ & $\%$ & $\mathbf{N}^{\circ}$ & $\%$ \\
\hline \multirow{7}{*}{$\begin{array}{l}\text { Quintil de } \\
\text { Pobreza }\end{array}$} & I & 70260 & $4,1 \%$ & 560190 & $6,3 \%$ \\
\hline & II & 86915 & $5,1 \%$ & 679237 & $7,7 \%$ \\
\hline & III & 167310 & $9,8 \%$ & 927009 & $10,5 \%$ \\
\hline & IV & 440480 & $25,7 \%$ & 2050620 & $23,2 \%$ \\
\hline & V & 943454 & $55,2 \%$ & 4596349 & $52,1 \%$ \\
\hline & Sin definir & 2155 & $0,1 \%$ & 13521 & $0,2 \%$ \\
\hline & Total & 1710574 & $100 \%$ & 8826926 & $100 \%$ \\
\hline \multirow{5}{*}{$\begin{array}{l}\text { Categoría de } \\
\text { IPRESS }\end{array}$} & Primer nivel & 1363925 & $79,7 \%$ & 7822157 & $88,6 \%$ \\
\hline & Segundo Nivel & 200583 & $11,7 \%$ & 667236 & $7,6 \%$ \\
\hline & Tercer Nivel & 146006 & $8,6 \%$ & 305939 & $3,5 \%$ \\
\hline & Sin definir & 60 & $0 \%$ & 31594 & $0,3 \%$ \\
\hline & Total & 1710574 & $100 \%$ & 8826926 & $100 \%$ \\
\hline
\end{tabular}

Respecto a la información de la plataforma Teleatiendo, los diagnósticos más frecuentes registrados tanto de telemonitoreo como de teleorientación fueron: actividades de promoción de la salud $(3,6 \%)$, COVID-19 virus identificado $(3,6 \%)$, hipertensión arterial $(2,8 \%)$ y consejos y asesoramiento general sobre anticoncepción (2,8\%).

Los datos muestran un volumen importante de telemonitoreo y teleorientación registrado por el MINSA, en consistencia con programas establecidos en países de la región como Brasil (3). Estos servicios pudieron evitar exposiciones innecesarias a contagios por COVID-19 por parte del personal de salud y usuarios, lograron capacitar a mayor cantidad de trabajadores ya que todos tuvieron acceso a las capacitaciones; además, debido a estas capacitaciones remotas, el personal de salud presencial permanecía en los establecimientos de salud pudiendo lograr mayor cobertura de servicios de salud en las zonas más alejadas del país.

La literatura científica menciona que no existen diferencias en relación a la eficacia del seguimiento remoto en comparación al seguimiento presencial en algunas patologías ${ }^{(4,5)}$; sin embargo, sus diferencias en costos y satisfacción de los pacientes pudieran ser relevantes ${ }^{(6)}$.

Nuestros hallazgos muestran que estos servicios se están concentrando en poblaciones con niveles de ingresos altos según su clasificación de pobreza; además muestran que la mayor cantidad de atenciones brindadas fueron registradas en servicios de salud del primer nivel de atención, siendo los establecimientos de salud del tercer nivel los que menos aportaron en el volumen total de telemonitoreos y teleorientaciones. En ese sentido, estos resultados demostrarían limitaciones de acceso a las iniciativas de telesalud, como cobertura de línea telefónica, equipo telefónico propio, entre otros, los cuales se sugiere sean objetivo de investigaciones futuras.

\section{REFERENCIAS BIBLIOGRÁFICAS}

1. Watson AR, Wah R, Thamman R. The Value of Remote Monitoring for the COVID-19 Pandemic. Telemed J E Health. 2020;26(9):1110-2. DOI: 10.1089/tmj.2020.0134

2. Decreto Legislativo $\mathrm{N}^{\circ} 1490$ [Internet]. 2020 [citado 15 de mayo de 2021]. Disponible en: https:// www.gob.pe/institucion/presidencia/normas legales/575965-1490

3. Graça TU de S, Santos AL, Yamamoto G, de Souza RW, Srougé MPP, Pacheco RL, et al. Telemonitoring programme on COVID-19 for a low-income community in Brazil: case study. BMJ Innov. 2021;7(2):342 6. DOI: 10.1136/bmjinnov-2020-000619

4. Pekmezaris R, Tortez L, Williams M, Patel V, Makaryus A, Zeltser R, et al. Home Telemonitoring In Heart Failure: A Systematic Review And MetaAnalysis. Health Aff Proj Hope. 2018;37(12):1983-9. DOI: 10.1377/hlthaff.2018.05087

5. Kew KM, Cates CJ. Remote versus face-to-face check-ups for asthma. Cochrane Database Syst Rev. 2016;4:CD011715. DOI: 10.1002/14651858. CD011715.pub2

6. Martínez-Garcia M, Bal-Alvarado M, Santos Guerra F, Ares-Rico R, Suárez-Gil R, RodríguezÁlvarez A, et al. Monitoring of COVID-19 patients by telemedicine with telemonitoring. Rev Clin Esp. 2020;220(8):472-9. DOI: 10.1016/j.rce.2020.05.013 